\title{
Challenges beyond F-Value, Water Activity and Glass Transition Concept in Determining Food Stability
}

\author{
Mohammad Shafiur Rahman \\ Department of Food Science and Nutrition, College of Agricultural and Marine Sciences \\ Sultan Qaboos University, Muscat, Sultanate of Oman \\ Tel: 9682414 1273, Fax: 96824413418 \\ E-mail: shafiur@squ.edu.om
}

\begin{abstract}
Theoretical concepts of F-value, water activity and glass transition are the most successful in determining food stability during food processing and storage. The water activity and glass transition concepts are progressed by combining these concepts in a stability map named as state diagram. The first part of this paper provides stability criteria based on Fvalue, water activity, glass transition and state diagram. The second part explains the recently proposed macro-micro region concept in the state diagram. In this concept, 13 micro-regions are mapped and then relative stability criteria between the micro-regions are postulated. Final part presents real challenges in combing different hurdles in food preservation.
\end{abstract}

\section{Introduction}

It is a challenge to the food scientists and engineers to determine food stability from a scientific basis rather than empiricism. The modern food processing developed at the end of the 1700s when the Napoleonic wars raged. As Napoleon pushed forward into Russia, his army was suffering more casualties from scurvy, malnutrition, and starvation. The French government offered 12,000 francs to anyone who could develop a method of preserving food. In 1795 Nicolas Appert, a chef took up the challenge. He had a theory that if fresh foods were put in airtight containers and sufficient heat applied, and then the food would last longer. Appert packed foods in bottles, corked them, and submerged them in boiling water, thus preserving them without understanding of bacterial spoilage. After 14 years of experimentation, in 1809 he won the prize and this was given to him by Napoleon himself ${ }^{1}$. In 1804 France military had opened their first vacuum-packing plant. Although the process was a French military secret, it soon leaked across the English Channel ${ }^{2}$. In 1810, an Englishman, Peter Durand, took the process a step further and developed a method of sealing food into unbreakable tin containers. This technique was perfected by Bryan Dorkin and John Hall, who set up the first commercial canning factory in England in $1813^{3}$

A theoretical understanding of the benefits of canning did not come until Louis Pasteur observed the relationships between microorganisms and food spoilage after fifty years later. By the 1860 s the time required to process food in can was reduced from 6 hours to $30 \mathrm{~min}$ through numbers of inventions and improvements. The sterilization of canned foods has a long tradition and it is most likely that it will continue to be popular because of its convenience and extended shelf-life (1-4 years at ambient temperature) and for being economic ${ }^{3}$. The time of sterilization process is estimated based on F-value concept.

In the 1950s scientists began to discover the existence of a relationship between the water contained in a food and its relative tendency to spoil. W. J. Scott, an Australian scientist, proposed that the active water could be much more important to the stability of a food than the total amount of water present. The legacy of Scott allowed scientist to develop generalized rules or limits for the stability of foods using water activity ${ }^{4}$. Labuza et al. ${ }^{5}$ proposed the earlier food stability maps based on the water activity concepts containing growth of micro-organisms and different types of bio-chemical reactions. Recently, an updated stability map was presented by Rahman ${ }^{1}$.

Scientists identified numbers of limitations of the water activity concepts and glass transition concepts in the literature. Glassy materials have been known for centuries but the glass transition concept was first applied to foods with scientific understanding in the $1980 \mathrm{~s}^{6}$. The glass transition concept postulated that foods are most stable at its glassy state (i.e. below glass transition temperature). White and Cakebread ${ }^{7}$ first highlighted the importance of the glassy state of foods in determining its structural stability. They were perhaps the first food scientists to discuss the importance of the glassy and rubbery states in relation to the collapse of a number of high solid systems. The significant applications of the glass transition concept emerged in food processing in the 1980s, when Levine and Slade ${ }^{8}$ and Slade and Levine ${ }^{9}$ identified its major merits and wide applications.

The glass transition concept was further advanced by developing a state diagram for foods. A state diagram is a stability map of different states and phases of a food as a function of water or solids content and temperature $^{10}$. Most probably Levine and Slade $^{8}$

*Corresponding Author: Mohammad Shafiur Rahman

E-mail: shafiur@squ.edu.om 
presented the first state diagram of providone $\mathrm{N}$-vinyl pyrrolidone (PVP) in the food science literature by illustrating glass line, freezing curve, and intersection of these lines as $T_{g}{ }^{\prime \prime}$ by extrapolation of the extended freezing curve by maintaining similar curvature. The main advantages of drawing a map are to help understanding the complex changes when the water content and temperature of foods are changed. It also assists in identifying stability of foods during storage as well as selecting a suitable condition of temperature and moisture content for processing. This state diagram provided four macro-regions. In the literature it was emphasized that a combination of water activity and glass transition concepts could be a powerful tool in predicting water activity. These approaches to combine both concepts are reviewed by Rahman ${ }^{11,12}$. Rahman ${ }^{13}$ combined glass transition and water activity concepts in the state diagram by plotting BET-monolayer values as a function of temperature.

A macro-micro region concept combing water activity and glass transition concepts in the state diagram was first presented in the $18^{\text {th }}$ International Congress of Chemical and Process Engineering (CHISA 2008), 2428 August 2008, Pragur, Czech Republic, and was subsequently published in the International Journal of food Properties ${ }^{1}$. Based on this, Rahman ${ }^{1}$ developed the state diagram and hypothesized 13 micro-regions having the highest to the lowest stability based on the location from glass transition and BET-monolayer lines. In the literature, water mobility and critical temperature concepts are also proposed to determine the food stability. The objective of this review is to explain the concepts of water activity, glass transition, state diagram, and macro-micro region in determining food stability.

\section{F-Value}

The inactivation target in sterilization process in canned products depends on the types of heat resistance bacteria and $\mathrm{pH}$ of foods. It is possible to classify food products into three groups according to $\mathrm{pH}$ : low-acid ( $\mathrm{pH} \geq 4.6)$, medium-acid $(3.7 \leq \mathrm{pH} \leq 4.6)$, and acid foods $(\mathrm{pH} \leq 3.7)$. The target microorganism in the thermal processing of low-acid food $(\mathrm{pH} \geq 4.6)$ is Clostridium botulinum. The processing time based on first order kinetics can be estimated as ${ }^{14,15}$ :

$t=-\frac{1}{k} \ln \left(\frac{N_{F}}{N_{o}}\right)=\left(\frac{D}{2.303}\right) \ln \left(\frac{N_{o}}{N_{F}}\right)$

Where, $k$ is the destruction rate constant $\left(\mathrm{s}^{-1}\right), N_{o}$ and $N_{F}$ are the initial and final numbers or concentrations of micro-organism, and $D$ is the decimal reduction time (s), respectively.
The above equation indicates that final concentration tends to zero when time tends to infinity, thus it would not be possible practically to reach a final concentration of zero for the target micro-organism. Considering this point, the commercial sterilization criterion should be defined so that it is possible to design a process that is safe but occurs within a finite time and which is economically and practically feasible ${ }^{3}$. According to Stumbo $^{16}$, commercial sterilization criterion was established arbitrarily.

The commercial sterilization criterion states that the minimum thermal process should reduce initial microorganism concentration by $10^{12}$. This is well known as 12D concept or "botulinum cook". The commercial sterilization was used for several reasons: (i) to determine safety margins, (ii) to determine cooking requirements, and (iii) to prevent the growth of thermphilic spoilage microorganisms. The probability argument says, in 12D treatment there will be one spore in $10^{12}$ cans ${ }^{15}$. Considering 100 million cans consumed per day, an estimate over a 100 -year period worldwide consumption will be $3.65 \times 10^{12}$ cans and the $12 \mathrm{D}$ criterion would predict three to four outbreaks every 100 years $^{3}$.

If we know $D_{T}$ value of target micro-organism at the temperature $T$, we can estimate the processing time to achieve $12 \mathrm{D}$. However, the processing time varies with the size of a can. Considering $D_{121.1}=0.21 \mathrm{~min}$ for $C$. botulinum, one spore per $\mathrm{g}$ and can size of $0.1 \mathrm{~L}$ (density: $1 \mathrm{~g} / \mathrm{cc}$ ), the processing time $(t)$ to achieve 12D is 2.94 min from Eq. $1^{3}$. Similarly if the can size is $5 \mathrm{~L}$, the processing time is $3.29 \mathrm{~min}$. Since any thermal process could not be performed at a specific temperature instead a varied temperature range during heating and cooling time, thermal death time $F_{o}$ is defined for processing as:

$F_{o}=\int_{0}^{t} 10^{\frac{T-T_{r}}{z}} d t$

Where $F_{o}$ is the processing time $(\mathrm{s}), F_{r}$ is the death time at a reference temperature, $T_{r}$ is the reference temperature and $z$ is the thermal resistance constant or z-value. Currently, a common commercial sterilization treatment for $C$. botulinum, $F_{o}$ is in the range of 6-8 min, although some companies use $F_{o}$ of $10 \mathrm{~min}$ or higher. Considering this processing time, $5 \mathrm{~L}$ can size and the minimum time requirement $(6 \mathrm{~min})$ at $121.1^{\circ} \mathrm{C}$, indicated $1.335 \times 10^{-25}$ spores per package. Applying the probability concept, we should expect one outbreak in several billion years (to be precise, one hundred thousand billion years). In fact, at least in the past 50 years no outbreak has been directly related to the sterilization criterion ${ }^{3}$. 


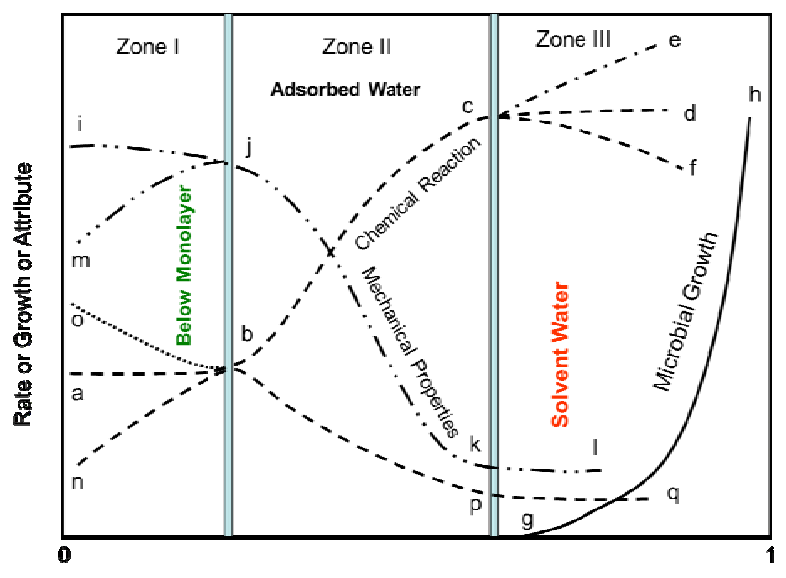

Fig. 1. Stability diagram based on the water activity concepts. gh: microbial growth trend; ob, ab, nb: chemical reaction trends below BET-monolayer; bc, bp: chemical reaction trends in the adsorbed water; ce, cd, cf, pq: chemical reaction trends in the solvent water region; ij, mj: mechanical properties trends below BETmonolayer; $\mathrm{jk}$ : mechanical properties trend in the adsorbed water region; kl: mechanical properties trend in the solvent water region (Rahman, 2009)

\section{Water Activity Concept}

Water activity indicates the state of water in foods. In general the rules of water activity concept are: (i) food products are most stable at their 'BET-monolayer" content or "BET-monolayer water activity" and unstable above or below BET-monolayer; (ii) there are a critical water activity limit for a specific microorganism or a class of micro-organism for their growth or toxin production, and biochemical reactions ${ }^{5,17-21}$. In the current food stability map, Rahman ${ }^{1}$ presented the trends of microbial growth, bio-chemical reactions and mechanical characteristics are presented in the three zones of water activity (Fig. 1). In fact, the BETmonolayer could be only achieved in the cases of dried foods. This water activity map provides the different dynamics for chemical reactions. For examples, below monolayer (zone I): (i) stability can be decreased with increasing water activity, for example fat oxidation (line ob); (ii) stability can remain constant (line ab); and (iii) stability can increase (line nb). In the adsorbed layer (zone II): (i) stability can increase (line bp); and (ii) stability can decrease (line bc). In multi layers (zone III): stability can increase, decrease or remained constant. The limitations of the water activity concepts are thoroughly reviewed by Rahman ${ }^{1}$.

\section{Glass Transition Concept}

Considering the limitations of water activity concept, the hypothesis of glass transition concept was put forward. Glassy materials show two major characteristics: inert (i.e. low molecular mobility), and brittle. The rules of the glass transition concept are: (i) the food is most stable at and below its glass transition (i.e. $T_{g}$ or $T_{g}{ }^{\prime}$ ), and (ii) the higher the $T-T_{g}$ or $T / T_{g}$ (i.e. above glass transition), the higher the deterioration or reaction rates ${ }^{9,22,23}$. It is clear from the literature that all experimental results could not be explained by the above rules ${ }^{1,13}$, thus further developments are necessary. The limitations of water activity and glass transition concepts would not invalidate the concepts completely rather make it difficult to apply universally. The water activity concept is based on the binding nature of water molecules in the matrix. When water is bound (i.e. unavailable to take part in reactions) to the solid matrix or non-solvent, then no deterioration reactions could be expected. The glass transition concept is based on the molecular mobility of the reacting components at micro-level in the matrix, thus diffusion of the reactants through the system to take part in reaction is very slow and stability is achieved. Thus a successful combination of water activity and glass transition could open more precise and unified determination of stability criteria. There should be a break (i.e. change in the slope between above and below the critical ratio) in the plot at $T / T_{g}$ equal to 1 if glass transition concept is valid or $X_{w} / X_{b}$ equal to 1 if water activity concept is valid. Considering the fact that glass transition is not the critical limit, Rahman ${ }^{11}$ tested the hypothesis that there is a critical temperature as a ratio of $T_{c} / T_{g}$, which could vary with moisture content. Above the critical temperature, an increase in the water content or temperature significantly increased the reaction rate while below the critical temperature the rate was relatively less affected by water content and temperature. He observed values of $T_{c} / T_{g}$ varied from 0.78 to 1.5 depending on the types of reaction and the matrices. In some instances, the values of $T_{c} / T_{g}$ were close to 1.0 indicating only glass transition could explain the process. Moreover the deviations of $T_{c} / T_{g}$ from 1 explained why in many instances in the literature both stability and un-stability was observed above and below glass transition.

\section{State Diagram}

The state diagram based of freezing curve and glass transition provided four macro-regions: region I (i.e. below glass transition), region II (above glass transition and below maximal-freeze-concentration, i.e. completely frozen, region III (above maximal-freezeconcentration condition and below freezing curve, i.e. partially frozen), and region IV (i.e. above glass transition and above freezing curve $)^{8,9,13}$. Rahman ${ }^{13}$ combine water activity and glass transition concepts in the state diagram by plotting BET monolayer as a function of temperature. This makes four regions: below BET-monolayer, one above and one below; and above BET-monolayer, one above and another below. 


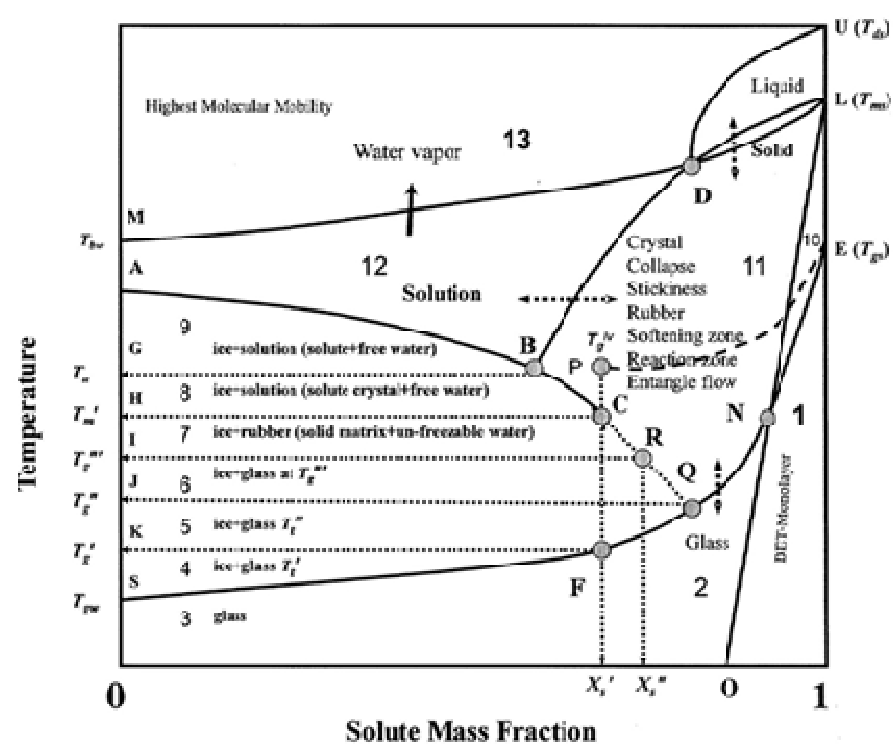

Fig. 2. State diagram showing different regions and state of foods, 1-13 indicate the micro-regions (updated from Rahman, 2006; Rahman, 2009)

\section{Macro-Micro Region Concept}

Rahman ${ }^{1}$ developed the state diagram as shown in Fig. 2 and hypothesized 13 micro-regions having the highest to the lowest stability based on the location from the glass transition and BET-monolayer lines. For example, region-1 (relatively non-reacting zone, below the BETmonolayer line and glass line) is the most stable and region-13 (highly reacting zone, far from BETmonolayer line and glass line) is the least stable. The stability decreased as the zone number increased. The most unstable micro-region is the region 13 since it is the most reactive mobile region. Applications of this concept in food processing are presented by $\operatorname{Rahman}^{12,13}$.

\section{Future Needs and Concluding Comments}

The water activity, glass transition or state diagram is the simplified nature of the real complexity. It would be interesting to incorporate other concepts in order to provide a more complete picture of food stability. The glass transition by thermal or mechanical relaxations measures mobility in a $20-300 \mathrm{~nm}$ range, while other relaxation techniques, such as Nuclear Magnetic Resonance (NMR) measures the molecular relaxation in a 1-2 nm range ${ }^{24}$. There are number of attempts are being made to relate glass transition and other mobility. However, generic trends or universal rules were unable to establish. All foods are not at BET-monolayer or below glass transition, thus other hurdles play roles in many foods. At present nearly more than 60 hurdles may involve in food preservation ${ }^{25}$. In combining several hurdles, such as water activity, storage temperature, $F_{o}$ value and $\mathrm{pH}$ into an unified theoretical foundation is a real challenge to the food scientists and engineering.

\section{Acknowledgement}

Dr. Rahman would like to thank the organizing committee of the $3^{\text {rd }}$ International Conference of Chemical Engineering, 29-30 December 2011, Dhaka, Bangladesh for inviting him to present this paper as a key note lecture. He would like to acknowledge the support of Sultan Qaboos University and his research team towards this research in the area of food structure and stability.

\section{Reference}

1. Rahman, M. S. (2009). Food stability beyond water activity and glass transition: Macro-micro region concept in the state diagram. Int. J. Food Properties. 12: 726-740.

2. Holdsworth, S. D., and Simpson, R. (2007). Thermal Processing of Packaged Foods, $2^{\text {nd }}$ edition, Springer, New York.

3. Simpson, R., Nunez, H., and Almonacid, S. (2012). Sterilization process design. Handbook of Food Process Design. First Edition. Ahmed, J. and Rahman, M. S. eds. Wiley-Blackwell, West Sussex, UK. p. 362-379.

4. Scott, W. J. (1953). Water relations of Staphylococcus aureus at $30 \mathrm{oC}$. Australian J. Biol. Sci. 6: 549-564.

5. Labuza, T. P., McNally, L., Gallagher, D., Hawkes, J., and Hurtado, F. (1972). Stability of intermediate moisture foods. I. Lipid oxidation. J. Food Sci. 37: 154-159.

6. Ferry, J. D. (1991). Some reflections on the early development of polymer dynamics: viscoelasticity, dielectric dispersion, and selfdiffusion. Macromolecules. 24: 5237-5245.

7. White, G. W., and Cakebread, S. H. (1966). The glassy state in certain sugar-containing food products. J. Food Technol. 1: 73-82.

8. Levine, H., and Slade, L. (1986). A polymer physico-chemical approach to the study of commercial starch hydrolysis products (SHPs). Carbohyd. Polym. 6: 213-244.

9. Slade, L., and Levine, H. (1988). Non-equilibrium behavior of small carbohydrate-water systems. Pure App. Chem. 60: 1841-1864.

10. Rahman, M. S. (2004). State diagram of date flesh using differential scanning calorimetry (DSC). Int. J. Food Properties. 7(3): 407-428.

11. Rahman, M. S. (2010). Food stability determination by macro-micro region concept in the state diagram and by defining a critical temperature. J. Food Eng. 99: 402-416. 
12. Rahman, M. S. (2012). Applications of macromicro region concept in the state diagram and critical temperature concepts in determining the food stability. Food Chem. 132: 1679-1685.

13. Rahman, M. S. (2006). State diagram of foods: Its potential use in food processing and product stability. Trends Food Sci. Technol. 17: 129-141.

14. Lewis, M., and Heppell, N. (2000). Continuous Thermal Processing of Foods. Aspen Publishers, Gaithersburg, Maryland.

15. Singh, R. P., and Heldman, D. R. (2009). Introduction to Food Engineering. Fourth Edition. Academic Press, Burlington, MA.

16. Stumbo, C. R. (1973). Thermobacteriology in Food Processing. Second Edition. Academic Press, New York.

17. Beuchat, L. R. (1981). Microbial stability as affected by water activity. Cereal Foods World. 26: 345-349.

18. Chirife, J. (1993). Physicochemical aspects of food preservation by combined factors. Food Control. 4: 210

19. Chirife, J. (1994). Specific solute effects with special reference to Staphylococcus aureus. J. Food Eng. 22: 409-419.
20. Drapron, R. (1985). Enzyme activity as a function of water activity. In: Properties of Water in Foods. Simato, D., Multon, J. L. eds. Martinus Nijhoff Publishers, Dordrecht.

21. Chirife, J., and Buera, M. D. P. (1996). Water activity, water glass dynamics, and the control of microbial growth in foods. Crit. Rev. Food Sci. Nutri. 36(5): 465-513

22. Slade, L., and Levine, L. (1991). Beyond water activity: recent advances based on an alternative approach to the assessment of food quality and safety. Crit. Rev. Food Sci. Technol. 30: 115-360.

23. Slade, L., and Levine, H. (1995). Glass transitions and water-food structure interactions. Adv. Food Nutrit. Res. 38: 103-269.

24. McBriety, V. J., and Packer, K. J. (1993). Nuclear Magnetic Resonance in Solid Polymers. Cambridge University Press, Cambridge, UK.

25. Leistner, L. (2000). Hurdle technology in the design of minimally processed foods. Minimally processed Fruits and Vegetables. Alzamora, S. M., Tapia, M. S., Lopez-Malo, A. eds. Aspen Publication, Maryland. 